accurately to assess the mortality from known HIV infection in a geographically defined population. The results underline the significance of the epidemic in Riverside, and it is likely that similar results would be found in other areas of the United Kingdom with a high prevalence of HIV infection.

After a long term decline death rates among young men in England and Wales have increased in most years since $1985 . .^{13}$ The reasons are not clear, and in particular it is not certain how much of the increase is due to HIV infection. ${ }^{1+15}$ McCormick has suggested that between $8 \%$ and $30 \%$ of deaths associated with HIV infection in young single men are not recognised through death certification and national surveillance. ${ }^{15}$ This study showed that in Riverside $94 \%$ of people dying of known HIV infection could be identified through national surveillance. The number of in dividuals dying before a diagnosis of HIV infection was made cannot be estimated from this study.

The study confirms that HIV or AIDS is rarely recorded on death certificates and that the confidential reporting system to the Office of Population Censuses and Surveys is infrequently used. As a result routine mortality statistics from the Office of Population Censuses and Surveys on the causes of death in young men are likely to be of limited value in areas with a significant mortality from HIV infection. This problem needs to be addressed. One solution would be to improve the recording of HIV and AIDS on death certificates - for example, by making information on the certified cause of death confidential. Alternatively, information from the national AIDS surveillance systems could be shared with the Office of Population
Censuses and Surveys to enable them correctly to code deaths due to HIV infection and thus ensure that mortality statistics accurately reflect the impact of HIV infection.

We thank Dr John Porter, Dr Noel Gill, Ms Choloud Porter, and Dr Anna McCormick for help and support.

1 Centers for Disease Control. Mortality attributable to HIV infection/AIDSUnited States, 1981-1990. MMWR 1991;40:41-4.

2 DeCock KM, Barrere B, Diaby L, Lafontaine MF, Gnaore E, Porter A, et ol. AIDS - the leading cause of adult death in the west African city of Abidjan Ivory Coast. Science 1990;249:793-6.

3 McCormick A. Trends in the mortality statistics in England and Wales with particular reference to AIDS from 1984 to April 1987. BMJ 1988;296: 1289-92.

4 Evans GE, Gill ON, Emslie JAN. Completeness of reporting of AIDS cases. BMF 1991;302:1351-2.

5 Bobby JJ, Spencer PD, Wyatt JC, Farmer RD'T. AIDS deaths in the UK how complete are the figures? Public Health 1988;102:519-24.

6 Hickman M, Aldous J, Durman L, Ellam A, Porter J, Shanson S. HIV seroprevalence in a defined London population. Lancet 1990;336:1328-9.

7 PHLS AIDS Centre-Communicable Disease Surveillance Centre, and Communicable Diseases (Scotland) Unit. Quarterly surveillance tables. No 11. London: PHLS, 1991

8 Hickman M, Aldous J, Porter J, Durman L. HIV surveillance in districts: the need for audit. BMF 1991;302:1376.

9 Fenna D. Phonetic reduction of names. Comput Methods Programs Biomed 1984;19:31-6.

10 Centers for Disease Control. Revision of the CDC surveillance case definition for acquired immunodeficiency syndrome. MMWR 1987;36 (suppl 1):3-15. 11 Centers for Disease Control. Premature mortality in the United States. MMWR 1986;35(suppl 2):1-1

12 McCormick A. Unrecognised HIV related deaths. BMf 1991;302:1365-7.

13 Department of Health and Social Security. On the state of the public health for the year 1989. London: HMSO, 1990.

14 McCormick A. Estimating the size of the HIV epidemic by using mortality data. Philos Trans R Soc Lond (Biol) 1989;325:163-73.

15 McCormick A. Excess mortality associated with the HIV epidemic in England and Wales. BMF 1991;302:1375-6.

\title{
Evidence of transmission of tuberculosis by DNA fingerprinting
}

\author{
Peter Godfrey-Faussett, Philip R Mortimer, P Anthony Jenkins, Neil G Stoker
}

\section{Abstract}

Objective-To determine whether a subject who had died of tuberculous meningitis had been infected by a neighbour.

Design-Retrospective comparison of isolates of Mycobacterium tuberculosis from the two cases and from 10 controls by DNA fingerprinting.

Setting-Public Health Service Reference Laboratory for Mycobacteria and bacterial molecular genetics unit of the London School of Hygiene and Tropical Medicine.

Subjects-Deceased and neighbour; 10 controls from the same city, from whom isolates had been collected over three months before the subject's death.

Main outcome measures-Identity and similarity values $\left(S_{A B}\right)$ between fingerprint patterns from different isolates obtained by hybridisation of restriction fragments produced by $P$ vull with a probe from the insertion element IS6110/986, present in multiple copies throughout the genome of $M$ tuberculosis.

Results-Isolates from the two cases under investigation had identical fingerprints whereas those from the controls were all distinct. Two clusters of isolates with a similarity coefficient $>0.25$ were identified: in one, four out of five patients were born in the midlands (the birth place of the fifth was not known) and in the other all three patients were born in the Indian subcontinent

Conclusions - The data are consistent with, but do not prove, transmission of tuberculosis from the neighbour to the deceased. Geographical separation of the pools of infection may have led to the evolution of distinct clusters of fingerprint patterns. DNA fingerprinting of $M$ tuberculosis is a powerful new tool for study of the epidemiology and pathogenesis of tuberculosis.

\section{Introduction}

The discovery of an DNA insertion element (variously named IS6110 or IS986) that is present as multiple copies scattered throughout the genome of 윽 Mycobacterium tuberculosis ${ }^{1}$ has allowed the develop- $N$ ment of DNA fingerprinting techniques for identifying $D$ different isolates. ${ }^{23}$ Although this insertion element must be mobile, the rate of change of the DNA fingerprint seems sufficiently slow to give these methods great epidemiological power.

After the death of a patient from tuberculous meningitis we were asked to help to determine whether the infection was likely to have been transmitted from a person living in the vicinity in whom cavitary, pulmonary disease had been diagnosed six months previously but who had not complied fully with treatment despite having been advised of the risk of infection. We believe that this is the first report of the use of this method in a forensic or public health investigation in the United Kingdom.

\section{Methods}

Isolates of $M$ tuberculosis were available from a postmortem meningeal biopsy specimen and from sputum cultured from the neighbour. Ten further isolates from the same city, collected over the three 
months before the patient's death, were used as controls. Four of the controls were from Asian immigrants, two of whom were born in India and two in Pakistan. The eight other isolates came from patients with British origins: six patients including the two under investigation, were born in the midlands, one was born in Scotland, and in one the place of birth was not known.

Isolates were grown on Lowenstein-Jensen slopes. Cells were scraped off the surface of the medium and resuspended in $1 \mathrm{ml}$ TE buffer $(10 \mathrm{mM}$ Tris $\mathrm{HCl} \mathrm{pH}$ 8.0, $1 \mathrm{mM}$ EDTA). DNA was extracted, digested with restriction endonuclease PvuII, electrophoresed through a $0.8 \%$ agarose slab gel, and vacuum blotted on to a nylon membrane (Hybond $\mathrm{N}+$, Amersham, United Kingdom) as described by Hermans et al. ${ }^{2+}$

A probe, 198 base pairs long, directed against the insertion element IS6110/986 was prepared by amplifying a segment of DNA with the polymerase chain reaction. ${ }^{5}$ The probe was labelled with horseradish peroxidase and hybridised to the membrane using an enhanced chemiluminescence kit (Amersham, United Kingdom). After exposing the membranes to luminol the positions of the insertion elements, indicated by enhanced chemiluminescence catalysed by peroxidase, were detected by exposing the membranes to Hyperfilm ECL (Amersham, United Kingdom).

DNA was extracted and digested on two separate occasions from each isolate, and some of the digests were electrophoresed on two separate gels to check consistency. Each membrane was exposed several times, with exposures varying from one minute to several hours.

"Fingerprints" of the same isolate run on different gels were compared between different autophotographs both visually and using a flat bed scanner and Gelreader program, version 1.0 (public domain software from the National Center for Supercomputing Applications, University of Illinois at UrbanaChampaign) to define the molecular weights of the fragments. Each isolate produced a consistent pattern; however the variability between the molecular weights calculated by the computer for the same band on different gels was greater than that between different bands on the same gel. The patterns from different isolates were therefore compared with each other visually. Similarity coefficients $\left(S_{\mathrm{AB}}\right)$ were calculated by the formula:

$S_{A B}=$ [number of bands shared between $A$ and $B] /[$ (number of bands in $A)+($ number of bands in B) - (number of bands shared between $A$ and $B$ )]

This is a simplification of the formula used by Schmid et al, ${ }^{\circ}$ and it ignores differences in intensity of hybridisation. These differences are not important; as PvuII cuts towards one end of the insertion sequence there will be only a single copy of the target on a given restriction fragment. If it is assumed that different restriction fragments can be distinguished on the gel each band should be an all or none signal. Identical isolates have an $S_{A B}$ value of 1.0 whereas isolates with no bands in common have a value of 0.0 .

A dendrogram was constructed with the method described by Schmid et al. ${ }^{6}$ This is a graphical representation of relatedness.

\section{Results}

Figure 1 shows fingerprints from the 12 isolates. The isolates from the dead patient and the neighbour ( 5509 and 8565) had identical fingerprint patterns, within the resolution of the gel. There were no other matching patterns among the remaining 10 isolates.

Figure 2 shows a dendrogram constructed from the similarity coefficients of all combinations of isolates. Two isolates (5354 and 7847) had an $\mathrm{S}_{\mathrm{AB}}$ value of 0.86 , which suggests that they diverged from a common ancestor more recently than other isolates. No specific epidemiological link was found between the patients to explain this. The $S_{A B}$ values were generally low. However there were two clusters (of five and three isolates) with $S_{A B}$ values of greater than $0 \cdot 25$, designated $A$ and $B$ in figure 2. Four of the five patients whose isolates fell in cluster A were born in the same city. The birth place of the fifth is unknown but her name is Anglo-Saxon. In contrast, all three patients whose isolates were members of cluster B were born in the Indian subcontinent.

\section{Discussion}

We showed that the $M$ tuberculosis strains isolated $\stackrel{\mathbb{D}}{\triangle}$ from both the deceased and the neighbour give identical fingerprints within the limits of this method. The accuracy of the analysis depends on defining visually which bands are shared between different lanes. The limiting factors are the resolution of the gel and minor variations in the separation achieved during electrophoresis. For isolates with only a few bands an error in determining whether a band matches another will have a larger effect on the similarity coefficient than for those with more bands.

The pattern seen in the index case and the deceased were not shared by 10 isolates from the same time and place. In studies in the Netherlands, where the epidemiology of tuberculosis is probably similar to that in the United Kingdom, unrelated isolates have always had unique fingerprint patterns, ' and our data support this. Clearly, the identity of the fingerprints does not prove that one patient passed the disease to the other. $\vec{\theta}$ Both could, for instance, have been infected by a N common source; however the matching pattern is consistent with transmission whereas a mismatch might have excluded it. A more classic epidemiological study showed that the index case was a likely source.
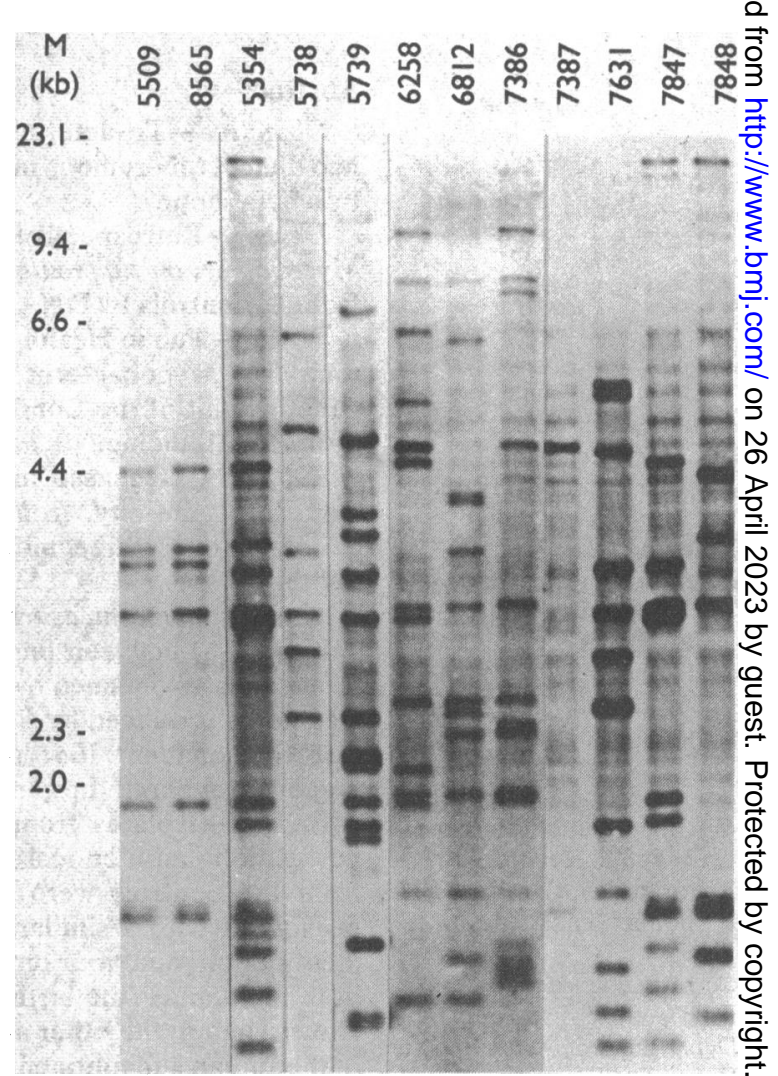

FIG 1-Fingerprint patterns of $M$ tuberculosis isolates. Lane $M$ molecular weight markers, lanes 5509 and 8565 isolates from deceased and neighbour, lanes 5354-7848 isolates from same time and city. (Composite figure of three different exposures of the same membrane, to compensate for different DNA loads) 
Place of birth

Pakistan

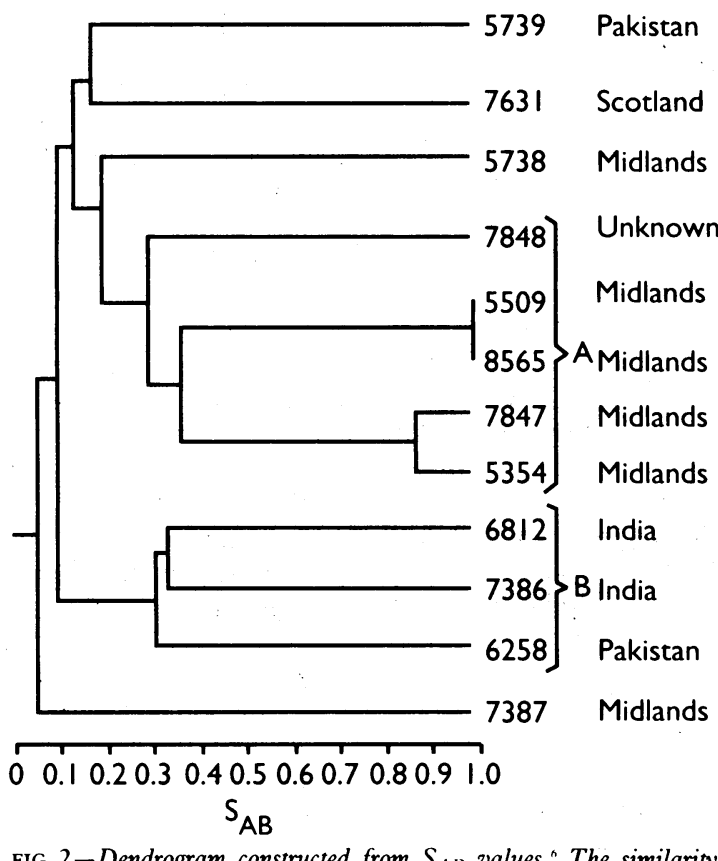

FIG 2-Dendrogram constructed from $S_{A B}$ values." The similarity between any two isolates or groups of isolates is represented by the horizontal position of the node joining them. Place of birth of patient is also shown

Symptomatic disease was present for some months before treatment was started, and cavities were present on the chest radiograph. Compliance with treatment was not complete. The two children who lived with the index case developed clinical tuberculosis, as did a close relative living in the same road, but $M$ tuberculosis was not cultured from these subjects. The fact that transmission may have occurred before the diagnosis prevents any conclusion regarding the behaviour of the index case.

Two isolates (7847 and 5354) were related, with an $S_{A B}$ value of $0 \cdot 86$, but no epidemiological link between them was found by reviewing their hospital records. Fingerprints based on insertion element IS6110/986 have been shown to be stable during passage through culture and guinea pigs, ${ }^{2}$ and did not change over several years in five patients with relapsed tuberculosis.? The factors governing how and when the insertion elements move are not yet known. Without a theoretical model and estimates of the probability of specific transpositions, $S_{A B}$ values are measures of the similarity of patterns and it is not possible to generate true phylogenetic distances between isolates. ${ }^{89}$ None the less, it is reasonable to assume that isolates related by higher $S_{A B}$ values evolved from common ancestors more recently than those with lower values.

Two clusters of isolates were found to have $S_{A B}$ values greater than $0 \cdot 25$. In one cluster four out of five of the isolates came from patients who had been born in the same city and the fifth also had an Anglo-Saxon name whereas in the other cluster all three patients had been born in India or Pakistan. Geographical separation of the pools of infection may have led over a long period to the evolution of distinct clusters of fingerprint patterns. The patterns seen in the immigrant group would then be the result of reactivation of infection acquired as children in Asia.

This study confirms the potential use of DNA fingerprinting techniques for studying routes of transmission of tuberculosis. As more data accumulate a global database of fingerprints should be established to support this early suggestion that cases form clusters by ethnic origin. Confirmation of this idea would allow old questions about the relative importance of reactivation and reinfection in the pathogenesis of tuberculosis to be addressed anew.

We acknowledge the collaboration of Dr J van Embden and his group in establishing this technique, $\mathrm{S}$ Hinshelwood for useful discussions, and Detective Inspector Sawers of West Midlands Criminal Investigation Department for his help. PG-F is funded by a Medical Research Council training fellowship, NGS is partly funded by the Overseas Development Administration.

Zainuddin Z, Dale J Polymorphic repetitive DNA seyuences in Mycobackerium tuberculosis detected with a gene probe from a Mycobacterium fortuitum plasmid. $\mathcal{F}$ (ien Microbiol 1989;135:2347-55.

2 Hermans PWM, van Soolingen D, Dale J, Schuitema A, McAdam R, Catty D, tt al. Insertion clement IS986 from Mycobacterium tubefculosis: a usclul tool for diagnosis and epidemiology of tuberculosis. $f$ clin Mirubial 1990;28:2052-8.

3 Mazurek (GH, Cave MD, Eisenach KD, Wallace RJ, Bates JH, Crawlord J' Chromosomal DNA fingerprint patterns produced with IS6110 as strainspecific markers for epidemiologic study of tuberculosis. I Clin Microbiol specific markers

4 Hermans PW, Schuitema ARJ, Van Sexlingen D, Verstynen C, Bik E, Thole J, et al. Specific detection of Mycobacterium tuberculesis complex strains by polymerase chain reaction. F C/in Microbiol 1990;28:1204-13.

5 Godfrey-Faussett P, Khoo S, Wilkins EGL, Stoker NG. Tuberculou pericarditis confirmed by DNA amplification. Lancet 1991;337:176-7.

6 Schmid J, Voss E, Soll DR. Computer assisted methods for assessing strain relatedness in Candida albicans by fingerprinting with the moderately repetitive sequence Ca3. J (in Microbiol 1990);28:1236-43.

7 Otal I, Martin C, Vincent-Levy-Frebault V, Thierry D, Gicuucl B. Restriction fragment length polymorphism analysis using IS6/I0 as an epidemiological marker in tuberculosis. F Clin Microbiol 1991;29:1252-4.

8 Bishop MJ, Friday AE, Thompson EA. Inference of evolutionary relationship In: Bishop MJ Rawlings CJ eds. Nucleic acid and protein seunencio unalysis, In: Bishop MJ, Rawlings CJ, eds. Nucletc actd and

9 Campbell A. Evolutionary significance of accessory DNA elements in bacteria Ann Rev Microbiol 1981;35:55-83.

(Accepted l fune 1992)

offices (Post Office Counters Ltd) were excluded from the analysis. All were visited and photographed 0 between July and October 1991. Details of the different sites used for tobacco advertising, of the type of items sold, and whether smoking was banned on the premises were collected. From the photographic record an estimate was made of the total area of advertising on each post office. Wards were defined as deprived if they had a Jarman score of 1 SD above the mean $\left(+16\right.$ or more). ${ }^{2}$

Eighty six post offices in 43 electoral wards (range 1-6 per ward) in Bristol were surveyed. Forty (46.5\%) of the 86 carried tobacco advertising, $31(36.0 \%)$ on windows, $18(20.9 \%)$ on nameboards, six $(7.0 \%)$ on sunblinds, and $14(16.3 \%)$ on other areas. Of the 40 post offices, half had advertising on one site only, 12 on two sites, and eight on three or more sites; 15 of the 40 $(37.5 \%)$ carried less than $1 \mathrm{~m}^{2}$ of advertising space, 10 (25\%) $1-2 \mathrm{~m}^{2}$, six (15\%) $2-3 \mathrm{~m}^{2}$, and nine $(22 \cdot 5 \%)$ over $3 \mathrm{~m}^{2}$.
Methods and results
The study included all Bristol sub post offices listed in the Yellow Pages telephone directory. Main post
Bristol and District Health Giok Ong, research assistant

\section{West Berkshire Health Authority \\ Aary Bolger, consultant in}

Correspondence to:

Dr Gray.

BMf 1992;305:223-4 and widely used by people of all ages. A study was aken to document the amount of tobacco tising on post offices in Bristol, to examine the relation advertising and deprivation, and to pro baseline data against which to monitor the effect recent voluntary agreement on shopfront advertising. 